\title{
Relationships between Perceived Teachers' Controlling Behaviour, Psychological Need Thwarting, Anger and Bullying Behaviour in High-School Students
}

Full citation: Hein, V., Koka, A., \& Hagger, M. S. (2015). Relationships between perceived teachers' controlling behaviour, psychological need thwarting, anger and bullying behaviour in high-school students. Journal of Adolescence, 42, 103-114.

doi:10.1016/j.adolescence.2015.04.003 


\section{Thwarting, Anger and Bullying Behaviour in High-School Students}

3 Bullying is defined as intentional verbal or physical aggressive behaviour with intent to harm and

4 typically involves an imbalance of power between the victim and perpetrator (Rigby, 2002).

5 Monks and Smith (2006) have classified bullying as a subset of aggression and several authors

6 have viewed a state anger as potential precursor to aggressive behaviour (Dodge, 1991; Price \&

7 Dodge, 1989). Bullying among school children is a major social problem globally (Nansel,

8 Craig, Overpeck, Saluja, \& Ruan, 2004). A study by Ziegler and Rosenstein-Manner (1991),

9 based on self-report data from children in Canada, showed that $8 \%$ of children reported are

10 bullied weekly and $20 \%$ of the respondents reported being bullied at least once per school term.

11 Furthermore, $74 \%$ of those bullied reported being hit or kicked, $23 \%$ reported being teased, and

$129 \%$ were threatened, intimidated, confined or suffered other types of bullying. According to the

13 results of the cross-national Health Behaviour of School-aged Children (HBSC) study, $41 \%$ of

14 schoolchildren aged 11 to 15 years in Estonia reported being a victim of bullying. Furthermore,

$1546 \%$ of students of this age reported engaging in bullying behaviour. Most important, however,

16 the HBSC study reported more frequent incidents of bullying among younger school children

17 aged 11 to 13 years in Estonia compared to other countries (Aasvee et al., 2012).

18 There are several reasons for bullying. Besides demographic risk factors related to

19 socioeconomic background like parental educational level and family income (Jansen et al.,

20 2012), the school environment in which the students spend a substantial part of their day may

21 have also impact on students' aggressive behaviour. Salmivalli and Peets (2009) have noted that

22 the classroom context plays an important role in the occurrence of school bullying. Teachers'

23 behaviour in the classroom context may play a central role in creating a positive or negative class 
1 climate that may have concomitant consequences on pupils' behaviour. In this article we

2 investigate the different dimensions of perceived teacher's controlling behaviour and perceived

3 thwarting of basic psychological needs from self-determination theory (SDT, Deci \& Ryan,

4 2000) as potential contributors to aggressive and bullying behaviour and negative affect in

5 Estonian school children.

\section{Controlling teacher behaviour ${ }^{1}$}

$7 \quad$ SDT is one of the most widely used approaches to explaining human behaviour (Deci \&

8 Ryan, 2000) and it has been applied intensively in educational contexts (Hagger \&

9 Chatzisarantis, 2007; Niemiec, Ryan, \& Deci, 2009). SDT posits that individuals strive to satisfy

10 three basic and universal psychological needs for autonomy (to feel self-determined in one's

11 actions rather than feeling controlled), competence (to feel competent in interactions with the

12 environment and experience opportunities in which to express one's capabilities), and

13 relatedness (to feel a secure sense of belongingness and connectedness to others) (Deci \& Ryan, 14 1985, 2000; Sheldon, Elliot, Kim, \& Kasser, 2001). According to SDT, the satisfaction of these

15 needs is related with social factors like school environment and teacher behaviour. A number of

16 studies in educational settings (Barkoukis, Hagger, Lambropoulos, \& Torbatzoudis, 2010;

17 Hagger, Chatzisarantis, \& Harris, 2006; Ntoumanis \& Standage, 2009; Reeve \& Jang, 2006;

18 Ryan \& Deci, 2000), including physical education among Estonian students (Hagger et al., 2009;

19 Pihu, Hein, Koka, \& Hagger, 2008), have demonstrated that autonomy-supportive teacher

20 behaviour is related directly or indirectly via need satisfaction with positive affective and

21 behavioural outcomes.

22 Although a large number of studies have examined the correlates of autonomy supportive

23 teaching styles, the correlates of controlling teaching styles has only recently received attention. 
1 Moreover, according to Vansteenkiste and Ryan (2013), controlling teaching behaviours should

2 be considered independent of autonomy-supportive behaviours and deserve separate attention in

3 the scientific literature. Recent studies in educational settings have demonstrated that teacher

4 controlling behaviours were related to lower levels of perceived psychological need satisfaction,

5 less engagement during the lessons (Cheon \& Reeve, 2015), increased levels of students'

6 controlled motivation and amotivation (De Meyer et al., 2014; Cheon \& Reeve, 2015), and

7 increased cortisol levels, a physiological marker of stress, among students (Reeve \& Tseng,

8 2011). Controlling teacher behaviours have also been shown to predict negative affect in students

9 during learning like anger and anxiety (e.g., Assor, Kaplan, Kanat-Maymon, \& Roth, 2005;

10 Flink, Boggiano, \& Barrett, 1990) and negatively related to overall academic achievement

11 (Soenens, Sierens, Vansteenkiste, Dochy, \& Goosens, 2012). It is noteworthy that studies have

12 consistently shown relatively modest correlations between subordinates' perceptions of their

13 supervisor's provision of autonomy support and controlling behaviours (Bartholomew,

14 Ntoumanis, \& Thøgersen-Ntoumani, 2010, Bartholomew, Ntoumanis, Ryan, Boch, \&

15 Thøgersen-Ntoumani, 2011; Pelletier, Fortier, Vallerand, \& Briere, 2001; Silk, Morris, Kanaya,

16 \& Steinberg, 2003; Tessier, Sarrazin, \& Ntoumanis, 2008), indicating that controlling behaviours

17 are not the conceptual opposite of autonomy supportive behaviours. According to Bartholomew,

18 Ntoumanis, Ryan, Boch, et al. (2011), individuals in a position of authority thus may

19 simultaneously use a variety of autonomy supportive and controlling behaviours and to varying

20 extents. For example, a teacher may use conditional regard as a discipline strategy, a controlling

21 behaviour, but may also provide a clear rationale for requested behaviours, and autonomy-

22 supportive behaviour. 
Controlling behaviour in teachers has been usually measured on a uni-dimensional scale

2 (Assor, et al., 2005; Reeve \& Halusic, 2009; Soenens et al., 2012). In their review of parental and

3 educational literature concerning the controlling strategies of significant others, Bartholomew,

4 Ntoumanis, and Thøgersen-Ntoumani (2009) identified several dimensions of controlling

5 behaviour (e.g., controlling use of praise and extrinsic rewards, negative conditional regard,

6 intimidation, excessive controlling behaviour, judging/devaluing, and promoting ego-

7 involvement). In their development and initial validation of the Controlling Coach Behaviours

8 Scale (CCBS), Bartholomew et al. (2010) proposed a conceptual model of controlling behaviours

9 comprising four controlling strategies by coaches: controlling use of praise and extrinsic

10 rewards, negative conditional regard, intimidation, and excessive controlling behaviour. In the

11 present study we focus on these four controlling strategies and adapt these to the physical

12 education context.

13 According to Bartholomew et al. (2009, 2010), controlling use of praise and extrinsic

14 rewards refers to the use of encouraging statements and extrinsic rewards by significant others to

15 reinforce desired behaviours by their subordinates. An example of the controlling use of praise is

16 a teacher who uses his or her positive feedback solely to direct the future behaviour of the

17 students, as opposed to providing information regarding present performance. An example of the

18 controlling use of extrinsic rewards is a teacher who promises to reward students if they engage

19 in tasks he or she sets them or perform to a specified standard (Deci, Koestner, \& Ryan, 1999). A

20 leader or social agent shouting at his or her subordinates to intimidate them into doing the things

21 he or she wants is a prime example of the use of intimidating behaviour. An example of

22 intimidating behaviour is a teacher who uses the threat of punishment (e.g., push-ups) to

23 motivate students to work harder or keep them in line during lessons or embarrasses students in 
1 front of their peers if they do not do certain things. Negative conditional regard refers to the

2 withdrawal of attention, affection, and support from the significant other when specified

3 behaviours by their subordinates are not displayed. An example of the negative conditional

4 regard is a teacher who says things to make a student feel guilty (e.g., 'you have really let me

5 down') when he or she does not perform well or behave as the teacher was expecting. Finally,

6 excessive controlling behaviour refers to behaviours adopted by significant others that can be

7 characterised as intrusive monitoring. An example of an excessive controlling behaviour is a

8 teacher who attempts to interfere in aspects of the students' lives that are not directly associated

9 with their schooling (e.g., teacher's duty to recruit students for extracurricular activities such as

10 competition between schools) and pressure them to prioritise his or her lesson over other lessons.

\section{The role of controlling teacher behaviours on basic psychological need thwarting and}

12 bullying behaviour

13 According to SDT, when psychological needs are satisfied people will develop and

14 function effectively, but if these needs are thwarted, people report lower levels of well-being and

15 experience non-optimal functioning (Bartholomew, Ntoumanis, Cuevas-Campos, \& Lonsdale,

16 2014; Deci \& Ryan, 2000). SDT also posits that the darker sides of human behaviour and

17 experience, such as certain types of psychopathology, prejudice, and aggression are understood

18 in terms of reactions to basic needs having been thwarted, either developmentally or proximally

19 (Deci \& Ryan, 2000). Researchers have noted that examining whether need thwarting has

20 meaningful and empirical consequences can provide more robust tests of SDT's account of the

21 darker sides of human behaviour (Bartholomew, Ntoumanis, \& Thøgersen-Ntoumani, 2011).

22 Studies have shown that whereas the satisfaction of psychological needs is directly or indirectly

23 related to multiple adaptive behavioural and affective outcomes such as vitality and positive 
1 affect (Baard, Deci, \& Ryan, 2004; Bartholomew, Noumanis, Ryan, Bosch, et al., 2011; Reeve \&

2 Jang, 2006; Ryan, Patrick, Deci, \& Williams, 2008), the thwarting of these needs can lead to

3 defensive or self-protective responses (e.g., compensatory motives or need substitutes, and rigid

4 behaviour patterns) that have significant negative affective or behavioural consequences such as

5 burnout, depression, and negative affect (Bartholomew, Noumanis, Ryan, Bosch, et al., 2011;

6 Demaray \& Malecki, 2002; Niemiec, et al., 2009; Ryan, Deci, Grolnick, \& La Guardia, 2006).

7 Research conducted in multiple contexts including education has demonstrated the

8 detrimental effect of controlling strategies of significant others on their subordinates' basic

9 psychological needs for autonomy, competence, and relatedness. Paying particular attention to

10 the controlling behaviours most relevant to the current study, praise from supervisors given non-

11 contingently, and perceived as inappropriate and insincere by subordinates, undermined their

12 feelings of competence and autonomy (Henderlong \& Lepper, 2002; Hollembeak \& Amorose,

13 2005; Horn, 1985; Kohn, 1993). Mageau and Vallerand (2003) suggested that if athletes perceive

14 their coaches to use conditional caring, either positive or negative, they were more likely to

15 relinquish their autonomy to maintain a satisfactory relationship with their coach. Barber (2001)

16 argued that the use of excessive controlling behaviour by parents can undermine children's needs

17 for autonomy and relatedness. Similarly, research by D'Arripe-Longueville, Fournier, and

18 Dubois (1998) revealed that sport coaches engaging in intimidating behaviours had a detrimental

19 effect on the overall psychological experiences of their athletes, indicating that intimidating

20 behaviours may impact negatively on all three psychological needs. Finally, as was pointed out

21 by Skinner and Wellborn (1994), a social environment in classes can also block the development

22 of the needs for competence, autonomy, and relatedness by providing inconsistency or chaos,

23 coercion, and neglect, respectively. 
Consequently, we contend that if students' basic needs for autonomy, competence, and

2 relatedness are thwarted, they may experience feelings of anger and anxiety and turn to

3 aggressive behaviour themselves. For example, if a student's genuine preferences are devalued

4 and his or her sense of autonomy has been diminished, it may lead to the use of direct and hostile

5 strategies to control his or her peers (Hawley, Little, \& Pasupathi, 2002). One may also argue

6 that if the student's need for competence is thwarted, he or she may have a desire to demonstrate

7 physical superiority or power over other students. Finally, we argue that if a student perceives his

8 or her belonging to a social group to be restricted, or feels isolated from others, thereby thwarting

9 the need for relatedness, he or she may turn to aggressive behaviour.

10 The present study

11 Although the positive role of teachers' autonomy supportive behaviour and need

12 satisfaction on students' different adaptive affective and behavioural outcomes are well

13 documented, there is a lack of research on the effect of teacher's controlling behaviours on

14 maladaptive outcomes related to anger and subsets of aggressive behaviour like school bullying.

15 A recently proposed model based on SDT suggests that the thwarting of basic psychological

16 needs may serve to mediate the link between these perceived controlling teacher behaviours and

17 maladaptive outcomes (Bartholomew et al., 2010), but there is no direct evidence for this process

18 model in the context of anger and bullying outcomes in a physical education context. The current

19 study aims to fill this gap in the literature.

20 The main aim of the present study, therefore, is to develop and validate a model to

21 understand the effect of students' perceptions of their teacher's controlling behaviours (e.g.,

22 controlling use of praise and extrinsic rewards, negative conditional regard, intimidation and

23 excessive controlling behaviour) on their feelings of anger and bullying via the mediation of 
1 perceived psychological need thwarting (see Figure 1). To address this aim, we administered

2 adapted versions of Bartholomew et al.'s (2010) multidimensional measure of teachers'

3 controlling behaviours, Bartholomew, Ntoumanis, Ryan, and Thøgersen-Ntoumani's (2011)

4 measure of perceived thwarting of the needs for autonomy, competence, and relatedness, and a

5 measure of anger and bullying behaviour to a sample of Estonian school students. Consistent

6 with the proposed model, we hypothesise that students' perceptions of physical education

7 teachers' controlling behaviours will be related to the development of feelings of anger and

8 bullying behaviour. We also expect perceived psychological need thwarting will mediate the

9 effect of the perceived teacher controlling behaviours on feelings of anger and bullying

10 behaviour. Finally, a feeling of anger was expected to act as a precursor to bullying behaviour

11 (Dodge, 1991; Price \& Dodge, 1989).

Methods

\section{Participants and Procedure}

Participants were school children ( $N=602 ; 309$ boys, 293 girls) aged 12 to 16 years ( $M$

15 age $=12.88, S D=1.37)$ from 10 schools in Estonia. Students were enrolled in physical education

16 as a compulsory lesson twice per week. Permission to carry out the study in each school was

17 obtained from the headteacher and ethical approval was granted from the university ethics

18 committee. The questionnaire was uploaded to the internet and information about the website

19 address was forwarded to each school's headteacher who, in turn, forwarded the information to

20 students. Next, consent from class teachers was obtained in lieu of parental consent. Students

21 completed the online questionnaire at their convenience. The purpose of the study was explained

22 and the guidelines for completing the questionnaire were provided. It was also emphasised that

23 the questionnaire was designed to measure students' general feelings about their PE teacher's 
1 behaviour and their self-reported frequency of aggressive behaviour. The questionnaire took

2 approximately 10 to 12 minutes to complete. The students were assured that their responses

3 would remain confidential.

4 Measures

Teachers' controlling behaviour. The multidimensional Controlling Coach Behaviours

6 Scale (CCBS) developed by Bartholomew et al. (2010) was adapted to measure students'

7 perceptions of the PE teachers' controlling behaviour. Participants were initially presented with a

8 common stem ("My PE teacher ....") followed by the items tapping the four subscales:

9 controlling use of praise and rewards (e.g., “... uses rewards/praise so that I stay focused on

10 tasks during lesson”), negative conditional regard (e.g., “... is less supportive of me when I am

11 not exercise and perform well”), intimidation (e.g., “... uses the threat of punishment to keep me

12 in line during lesson”), and excessive controlling behaviour (e.g., ".... tries to control what I do

13 during my free time out of school"). Each of the four subscales comprised three items. Previous

14 research have supported the reliability and factor structure of the subscales of the CCBS using

15 confirmatory factor analysis (CFA) (Bartholomew et al., 2010).

16 The need thwarting scale. Students' perceptions of the thwarting of the psychological

17 needs of autonomy, competence, and relatedness in physical education were assessed using an

18 adapted and translated version of the 12-item Psychological Need Thwarting Scale (PNTS;

19 Bartholomew, Ntoumanis, Ryan, \& Thøgersen-Ntoumani, 2011). Example items were: "I feel

20 pushed to behave in certain ways" (autonomy thwarting), "There are times when I am told things

21 that make me feel incompetent " (competence thwarting), and "I feel I am rejected by those

22 around me" (relatedness thwarting). Bartholomew, Ntoumanis, Ryan and Thøgersen-Ntoumani

23 (2011) have reported adequate reliability statistics for the PNTS and supported its three-factor 
1 structure using CFA. In line with a work of Baard et al. (2004), and recent work in physical

2 education context (e.g., Taylor, Ntoumanis, \& Standage, 2008), scores for each subscale were

3 combined into a single latent variable and used as indicators of an overall need thwarting factor

4 in our hypothesized structural model. Participants responses to the CCBS and PNTS were made

5 on seven-point scales ranging from 1 (strongly disagree) to 7 (strongly agree).

6 Bullying behaviour and anger. Bullying behaviour and anger were measured using the

7 Modified Aggression Scale (MAS) developed by Bosworth, Espelage, and Simon (1999). Five

8 items of this instrument measure bullying behaviour and four items anger. For bullying

9 behaviour, participants were asked how many times they did the following in the past 30 days: "I

10 called other students names", "I teased students"; "I said things about students to make other

11 students laugh"; "I threatened to hit or hurt another student"; and "I pushed, shoved, slapped, or

12 kicked other students". For anger, participants asked how often they did the following in the past

1330 days: "I was angry most of the day"; "I took my anger out on an innocent person"; "I

14 frequently got angry"; and "I was grouchy or irritable, or in a bad mood, so that even little things

15 would make me mad". Responses were made on four-point scales with scale points: $0=$ never, 1

$16=1$ or 2 times, $2=3$ or 4 times, and $3=5$ or more times. Previous research has confirmed the

17 reliability (Bosworth et al., 1999; Espelage, Bosworth, \& Simon, 2000) and the two-factor

18 structure of this scale (Bosworth et al., 1999).

19 Translation Procedures

20 Estonian versions of the questionnaires for the present study were developed using

21 standardised back-translation procedures by two independent bi-lingual translators (Brislin,

22 1986). The back-translation procedure was repeated iteratively until the original and back-

23 translated English versions of the questionnaires were virtually identical. 


\section{Data Analyses}

2 Study hypotheses were tested using confirmatory factor analysis (CFA) and structural

3 equation modeling (SEM) with the LISREL 8.8 statistical package. ${ }^{2}$ Corrected maximum

4 likelihood estimation method was used. Model adequacy was evaluated by using multiple

5 goodness-of-fit indexes: comparative fit index (CFI), normed fit index (NFI), the non-normed fit

6 index (NNFI), and the root mean square error of approximation (RMSEA). A cut-off value

7 greater than .95 for the CFI, NFI, and NNFI, and a cut-off value less than or equal to .08 for the

8 RMSEA indicated adequate model fit (Hu \& Bentler, 1999). Indirect effects were computed

9 using LISREL's indirect effects matrix with correction for multiple mediation effects. In order to

10 examine the hypothesized model, we followed the three of Mulaik and Millsap's (2000) four

11 steps for confirming the factor structure of multi-item scales of recommendations. First, separate

12 CFA models that assumed discriminant validity between items representing four modified CCBS

13 factors, three modified PNTS factors and two Modified Aggression Scale factors, respectively,

14 were compared to corresponding congeneric CFA models that assumed lack of discriminant

15 validity for the observed scales. Specifically, each CFA model that assumed discriminant validity

16 between factors was specified by setting items of the respective latent constructs to load on their

17 expected factors. Also, in each CFA model that assumed discriminant validity between factors,

18 the latent constructs were set to correlate. Further, each corresponding congeneric CFA model

19 that assumed lack of discriminant validity was specified in which a single factor would explain

20 relationships between the items of different latent constructs. Discriminant validity of the

21 components is supported if the CFA model that hypothesizes discriminant validity satisfies

22 published cut-off criteria for indices of good fit and is superior in fit to the congeneric model in

23 which all items are specified to indicate a single latent construct. Second, the CFA was 
1 performed to verify the measurement model. Third, pending a satisfactory fit was obtained for

2 the measurement model, we tested the proposed model relations using SEM. The fourth and final

3 step of the procedure in which pre-specified paths that were freed in the model from its inception

4 are tested against unspecified paths was not relevant in the current model given the theory-based

5 nature of our specified model.

\section{Results}

\section{Preliminary Analysis} coefficients for all measures are presented in Table 1. Analyses of the skewness and kurtosis

10 values for the individual items revealed that not all data were normally distributed and therefore

11 the polychoric correlations and the asymptotic covariance matrices were used in subsequent CFA 12 and SEM analyses. The factor loadings and residuals for the CFA models for the modified

13 CCBS, modified PNTS, and MAS are presented in Tables 2, 3 and 4, respectively.

First, the discriminant validity CFA model for the modified CCBS with four latent factors

15 and 12 items (Table 5, Model 1) met the criteria for good fit and was superior in fit to the

16 congeneric model (Table 5, Model 2). The CFA model for modified PNTS with three factors and

1712 items exhibited inadequate fit $\left(\chi^{2}=318.75, \mathrm{df}=51, \mathrm{RMSEA}=.098\right.$ with $\mathrm{CI}_{90}=.088-.110$,

$18 \mathrm{NNFI}=.094, \mathrm{NFI}=.95, \mathrm{CFI}=.095)$. Results revealed low factor loading $(.25)$ for one item from

19 the perceived need thwarting for autonomy subscale: "I feel under the pressure to agree with the

20 exercises designed for me". Also, the standardized residual for this item and the item "I feel

21 obliged to follow exercise decision made for" was very high (20.43). After removing the item

22 with low factor loading, the composite reliability coefficient of this scale increased from .731 to

23 .780. The exclusion of this item also resulted in improved psychometric parameters that reached 
1 an acceptable level. The discriminant validity CFA model for the modified PNTS with three

2 latent factors and 11 items (Table 5, Model 3) met the criteria for good fit and was superior in fit

3 to the congeneric model (Table 5, Model 4). The discriminant validity CFA model for the

4 Modified Aggression Scale with two latent factors and 9 items (Table 5, Model 5) met the

5 criteria for good fit and was superior in fit to the congeneric model (Table 5, Model 6). All factor

6 correlations between the latent variables in each instruments were significantly different from

7 unity according to the criteria specified by Bagozzi and Kimmel (1995), supporting the

8 discriminant validity of the constructs.

9 Second, we tested our hypothesized measurement model based on 24 observed measures

10 and nine latent constructs, representing the four factors of modified CCBS (comprising 12

11 items), the three factors of PNTS (comprising 11 items) and two factors of Modified Aggression

12 Scale (comprising 9 items). The latent factors were allowed to correlate freely during assessment

13 of the measurement model (Anderson \& Gerbing, 1988). The results from the CFA revealed that

14 the measurement model was appropriate (Table 5, Model 7), where each factor was adequately

15 explained by its respective set of indicator items. In addition, factor correlations among the

16 constructs were significantly different from unity according to the criteria specified by Bagozzi

17 and Kimmel (1995), supporting the discriminant validity of the constructs.

\section{Main Analysis}

19 The main purpose of the SEM was to examine how students' perceptions of the different

20 dimensions of their teacher's controlling behaviour (controlling use of rewards, negative

21 conditional regard, intimidation and excessive controlling behaviour) were related to anger and

22 bullying via the mediation of the perceived thwarting of their basic psychological needs (see

23 Figure 1). A SEM was used to test a model with direct paths from the dimensions of the 
1 perceived teachers' controlling behaviour to perceived need thwarting and from perceived need

2 thwarting to anger and bullying. The subscale scores of each perceived need thwarting (i.e.,

3 thwarting of the need for autonomy, competence and relatedness) were used as indicators of an

4 overall perceived need thwarting latent variable. Also, the indirect effects from the dimensions of

5 perceived teachers' controlling behaviour on students' aggressive behaviour were calculated.

6 The structural model demonstrated a good fit with the data. ${ }^{3}$ The fit indices are presented

7 in Table 5 (Model 8) and standardized coefficients are presented in Figure 1. Overall, the model

8 explained $68 \%, 30 \%$, and $12 \%$ of the variance in perceived psychological need thwarting,

9 bullying, and anger latent factors, respectively. Focusing first on the effects of the four

10 controlling behaviour dimensions, students' perceptions of the negative conditional regard and

11 intimidation exhibited by the teacher were uniquely significantly related to students' perceived

12 psychological need thwarting. There were no unique significant effects for the controlling use of

13 praise and rewards, and excessive controlling behaviour on need thwarting. Focusing on the

14 effects of psychological need thwarting on outcomes, there was a statistically significant direct

15 path from perceived need thwarting to anger, but no statistically significant direct path from

16 perceived need thwarting to bullying. However, anger was strongly related to bullying and there

17 was also a significant indirect effect of perceived need thwarting on bullying via anger (see

18 Table 6). It was also hypothesized that perceived controlling teacher's behaviours would be

19 indirectly related to anger and bullying via perceived need thwarting. An examination of the

20 indirect effects indicated that the perceived negative conditional regard and intimidation were

21 statistically significantly related to students' anger and bullying, supporting our hypothesis for

22 these variables, but rejecting the hypotheses for the effects of the controlling use of praise and

23 rewards, and excessive controlling behaviour on the outcomes mediated by psychological need 
1 thwarting (see Table 6). Although the observed indirect effects of the dimensions of perceived

2 negative conditional regard and intimidation on students' anger were stronger than the indirect

3 effects of these constructs on students' bullying behaviour, there were no statistically significant

4 differences across the two predicted variables as indicated by the overlap in the $95 \%$ confidence

5 intervals (see Table 6).

\section{Discussion}

7 The purpose of this study was to investigate whether the perceptions of physical

8 education teachers' controlling behaviours by students were related to students' perceived

9 psychological need thwarting, feelings of anger, and bullying behaviour. Based on self-

10 determination theory, we hypothesised that the different dimensions of perceived controlling

11 behaviours of teachers would be related to maladaptive outcomes of anger and bullying mediated

12 by perceived thwarting of psychological needs.

13 Prior to testing hypotheses, we needed to confirm the validity of the psychological

14 measures constructs adapted for use with the current Estonian sample and in a physical education

15 context. Three scales measuring the multidimensional aspects of controlling behaviours (CCBS;

16 Bartholomew et al., 2010), psychological needs thwarting (PNTS; Bartholomew et al., 2011),

17 and the feelings of anger and bullying behaviour (MAS; Bosworth et al., 1999) were subjected to

18 CFA to confirm their construct and discriminant validity. In each case, the analyses revealed

19 acceptable psychometric properties and each factor was adequately explained by its respective

20 set of indicator items. The only exception was the CFA of the adapted version of the PNTS

21 (Bartholomew, Ntoumanis, Ryan, \& Thøgersen-Ntoumani, 2011) which led to a deletion of one

22 item from the perceived need thwarting for autonomy subscale ("I feel under the pressure to

23 agree with the exercises designed for me") that was removed due to low factor loading. In 
1 Estonia, individual design for exercise is not a common practice among PE teachers given the

2 curriculum requirements so future studies may consider rewording the item to refer to designing

3 activities for the class (e.g., “...exercises designed for the class”). This item aside, the analysis

4 supported the construct validity of the scale.

5 Focusing on the main hypotheses of the study, our structural equation model revealed that

6 different dimensions of perceived controlling behaviours of the physical education teacher were

7 positively related to students' perceived need thwarting. This was in keeping with our original

8 hypothesis. However, the proposed relations were confirmed for only two of the dimensions

9 (intimidation and negative conditional regard) with no unique effects for the others (controlling

10 use of praise and extrinsic reward and excessive controlling behaviour). These findings suggest

11 that the more students reported that their teachers used intimidation (e.g., verbal abuse, shouting,

12 physical punishment, humiliating and belittling behaviour, and personal attacks) when

13 communicating with the class, the more they felt that their basic psychological needs were

14 thwarted. Further, if the students were more likely to report that their teachers used negative

15 conditional regard (e.g., focusing less on student when he or she is struggling or offering no

16 attention, affection, and support when the student is not behaving as asked), their perceptions of

17 basic psychological needs were also more likely to be more thwarted. This is, to some extent,

18 consistent with findings of Blanchard, Amiot, Perreault, Vallerand, and Provencher (2009) who

19 demonstrated that coaches' controlling behaviour measured by unidimensional scale were

20 negatively related to the satisfaction of the need for autonomy.

21 In addition, Bartholomew et al. (2009) argued that some of the controlling motivational

22 strategies could be more damaging to young athletes' psychological well-being than others. They

23 suggested that controlling motivational strategies such as intimidation, negative conditional 
1 regard and guilt-induction will have stronger negative relationships with athlete well-being,

2 compared to strategies such as the use of extrinsic rewards. Our findings are consistent with

3 these proposals. That perceived intimidation and negative conditional regard in the present study

4 are the most damaging behaviours to well-being is not surprising as previous research on parents

5 has demonstrated these types of behaviours are associated with severe negative effects on the

6 well-being of those subjected to them as well as serious forms of psychological ill-being (e.g.,

7 Barber, 1996; Hewitt \& Flett, 1991). To the best of our knowledge, however, this is the first

8 study that has examined these effects in physical education teachers.

$9 \quad$ The student perceptions that their physical education teachers' used excessive controlling

10 behaviour and controlling use of praise and extrinsic rewards did not have a uniquely significant

11 relationship with students' perceived basic psychological need thwarting. There are several

12 possible reasons for these non-significant effects. First, the nature of the teacher-student

13 interaction in the latter types of controlling behaviours is less blatantly negative relative to the

14 effects of the intimidation and negative conditional regard behaviours (Bartholomew et al.,

15 2009). Second, physical education as a subject is consistently rated by students as one of the

16 most popular subjects in school, while its perceived importance relative to other 'academic'

17 subjects (e.g., mathematics, science, languages) is rated much lower (Ormerod, 1975; Stables \&

18 Wikeley, 1997). One may argue, therefore, when the physical education teachers pressure

19 students to prioritise physical education over other 'academic' subjects, the pressure is not taken

20 particularly seriously. The same might be true with physical education teachers' attempts to

21 control students' behaviour by promising to reward them if they engage in the tasks he or she has

22 set them. Consequently, although perceived incidence of these behaviours was relatively high

23 (e.g., the mean score of the controlling use of praise and extrinsic rewards was above the 
1 midpoint of the scale; see Table 1), it is fairly understandable why the controlling use of praise

2 and extrinsic rewards, as well as the use of excessive controlling behaviour, were not

3 substantially related to students' perceived psychological need thwarting in physical education

4 compared with teachers' intimidation and negative conditional regard.

5 Significant indirect effects from perceived negative conditional regard and intimidation

6 on students' anger and bullying behaviour were found via the mediation of perceived need

7 thwarting. It is noteworthy that the indirect effects of perceived negative conditional regard and

8 intimidation on anger were stronger than for the indirect effects on bullying. In general, results

9 confirmed our second hypothesis that students' perceptions of controlling behaviours used by

10 their teacher were indirectly related with anger and bullying via perceived need thwarting. This

11 finding also supports one of the main tenets of Deci and Ryan's (2000) SDT that the relationship

12 between social factors such as perceived teacher's controlling behaviour and students' affective

13 and behavioural outcomes such as feelings of anger and aggressive behaviour will be mediated

14 by the satisfaction or dissatisfaction of the basic psychological needs for autonomy, competence,

15 and relatedness. This finding is also consistent with previous results that indicated the role of the

16 need thwarting as the mediator between the relationship of job pressure and burnout among

17 physical education teachers (Bartholomew et al., 2014).

18 The proposed model showed that the anger was strongly related to bullying behaviour.

19 This finding supports hypotheses proposed by Dodge (1991) and Price and Dodge (1989) who

20 view anger as precursor of aggressive behaviour. Our specified alternative models further

21 supported the view that feelings of anger is a precursor of students' bullying behaviour.

22 We contend that the statistically significant relationship between perceived need thwarting and

23 bullying behaviour that was completely mediated by anger (i.e., a significant indirect effect with 
1 no direct effect) suggests that disaffection in terms of one's basic need satisfaction in physical

2 education may be related to the feelings of anger, which in turn, are linked to aggressive

3 behaviour toward other students. This indicates that negative emotional responses are implicated

4 in the process by which perceived need thwarting impacts on aggression. This is consistent with

5 hypotheses from a number of theories relevant to the current research. According to SDT, need

6 thwarting is not only related to changes in motivational orientations toward particular behaviours

7 but also maladaptive outcomes including emotional responses, such as frustration and, at times,

8 anger. Whether or not perceived basic need thwarting in physical education will result in feelings

9 of anger may depend on the importance students attach to physical education, as discussed

10 earlier. Similarly, in frustration-aggression theory (Dollard), frustration and anger evoked by

11 frustration of goal may lead to aggression, including aggression directed at targets that were not

12 the original source of the aggression. Together, these hypotheses indicate that the interplay

13 between perceived need thwarting and aggression may reflect a key process by which organismic

14 needs explain the subsequent behaviour.

15 Limitations

16 Although the present study provided some unique findings for the relationship between

17 students' perceptions of their physical education teachers' use of controlling behaviour and

18 students' aggressive behaviour, there are also some limitations that must be acknowledged. First,

19 the sample used in this study should be considered as the convenience sample that may not be

20 representative of the student population in Estonia. Future studies should focus on randomly

21 selected, stratified samples to permit better inference of findings to the population. The second

22 limitation was that the data only permitted us to determine individual- and school-level variance,

23 but not class-level variance in behaviour. Researchers should, therefore, consider collecting full 
1 data at the individual, class, and school levels in order to test all possible sources of variance in

2 the prediction of the psychological variables in the model tested in the current study. Third, the

3 data from the present study were based entirely on students' self-reports. Although, the cautious

4 should be exercised when interpreting self-reports of students, researchers (e.g., Anderson \&

5 Walberg, 1974; Fraser, 1989; Scriven, 1988) have claimed that students' subjective ratings about

6 learning environment as well as teacher's behaviours and about themselves are comparatively

7 valid. Fourth, the data are correlational in nature, which precludes the inference of causality. The

8 possibility still remains that students' who engage in bullying behaviour themselves may feel

9 anger and consequently perceive their teacher to exhibit higher degrees of controlling

10 behaviours. It is also possible that angry, aggressive adolescents are more sensitive to basic

11 psychological needs not being met. Future research would do well to explore the role that

12 feelings of anger play in the motivational sequence proposed in SDT. It is also possible that

13 examining the relations between other psychological variables such as global or physical self-

14 esteem and bullying behaviour may give more useful information. These possible alternatives

15 could be tested in future research by adopting a cross-lagged panel design measuring the

16 psychological antecedents of bullying behaviour and self-reported bullying behaviour and anger

17 at two points in time and analysing for reciprocal relations between the variables over time.

18 Another direction of future research would be to examine the role of observed actual controlling

19 teaching behaviours in physical education on corresponding perceived controlling teaching

20 behaviours and maladaptive affective and behavioural outcomes such as feelings of anger and

21 bullying behaviour (De Meyer et al., 2014).

22 Overall, findings of the present study are unique because they provide additional

23 empirical support for the role of perceived psychological need thwarting in SDT's theoretical 
1 account of the darker sides of human existence and enable a better understanding of the

2 processes related to aggressive behaviour in school students. In terms of implications for school

3 practice the model will help the physical education teachers to better understand how perceptions

4 of their controlling behaviour are related with students' perceived need thwarting and how this is

5 related with negative affective and behavioural outcomes. Based on the findings of the present

6 study, physical education teachers should be encouraged to avoid intimidating and guilt-inducing

7 behaviours in their lessons as these kinds of behaviours are related to the students' experience

8 that their basic psychological needs are thwarted. The controlling types of behaviours are also

9 related to feelings of anger and bullying behaviour toward others, both of which are aversive and

10 maladaptive outcomes for the students. Although the results of the present study did not

11 demonstrate the unique, statistically significant effects of over-intrusive behaviour (i.e.,

12 excessive controlling behaviour) and controlling use of praise and extrinsic rewards on students'

13 basic psychological need satisfaction, the positive, statistically significant correlations between

14 these dimensions and students' perceived need thwarting suggest that physical education

15 teachers should also avoid these types of behaviours when communicating with their students. 
2 Aasvee, K., Eha, M., Härm,T., Liiv, K., Oja, L., \& Tael, M. (2012). Eesti kooliõpilaste

3 tervisekäitumine. 2009/2010 õppeaasta Eesti HBSC uuringu raport. Tervisearengu instituut.

4 Social determinants of health and well-being among Estonian young peole. Estonian Report 5 from 2009/2010 survey. National Institute for Health Development.

6 Anderson, G. J. \& Walberg, H. J. (1974). Learning environments. In H. J. Walberg (Ed.),

7 Evaluating educational performance: A sourcebook of methods, instruments, and examples.

8 Berkeley: McCutchan.

9 Anderson, J. C., \& Gerbing, D. W. (1988). Structural equation modelling in practice: A review 10 and recommended two-step approach. Psychological Bulletin, 103, 411-423. doi:

$11 \quad$ 10.1037/0033-2909.103.3.411

12 Assor, A., Kaplan, H., Kanat-Maymon, Y., \& Roth, G. (2005). Directly controlling teacher 13 behaviors as predictors of poor motivation and engagement in girls and boys: The role of $14 \quad$ anger and anxiety. Learning and Instruction, 15, 397-413. doi:

16 Baard, P. P., Deci, E. L., \& Ryan, R. M. (2004). Intrinsic need satisfaction: A motivational basis 17 of performance and well-being in two work settings. Journal of Applied Social Psychology, 34, 2045-2068. doi: 10.1111/j.1559-1816.2004.tb02690.x

19 Bagozzi, R. P., \& Kimmel, S. K. (1995). A comparison of leading theories for the prediction of goal-directed behaviours. British Journal of Social Psychology, 34, 437-461. doi: 10.1111/j.2044-8309.1995.tb01076.x

22 Barber, B. K. (2001). Intrusive parenting: How psychological control affects children and 23 adolescents. Washington, DC: American Psychological Association. 
1 Barkoukis, V., Hagger, M. S., Lambropoulos, G., \& Torbatzoudis, H. (2010). Extending the

2 trans-contextual model in physical education and leisure-time contexts: Examining the role

3 of basic psychological need satisfaction. British Journal of Educational Psychology, 80,

4 647-670. doi: 10.1348/000709910X48702

5 Bartholomew, K. J., Ntoumanis, N., \& Thøgersen-Ntoumani, C. (2009). A review of controlling

6 motivational strategies from a self-determination theory perspective: Implications for sports

$7 \quad$ coaches. International Review of Sport and Exercise Psychology, 2, 215-233. doi: $10.1080 / 17509840903235330$

9 Bartholomew, K. J., Ntoumanis, N., \& Thøgersen-Ntoumani, C. (2010). The controlling interpersonal style in a coaching context: Development and initial validation of a psychometric scale. Journal of Sport and Exercise Psychology, 32, 193-216.

Bartholomew, K., Ntoumanis, N., Ryan, R., Bosch, J., \& Thøgersen-Ntoumani, C. (2011). Selfdetermination theory and diminished functioning: The role of interpersonal control and

4
psychological need thwarting. Personality and Social Psychology Bulletin, 37, 1459-1473.

16 Bartholomew, K., Ntoumanis, N., \& Thøgersen-Ntoumani, C. (2011). Self-determination theory 17 and the darker side of athletic experience: The role of interpersonal control and need thwarting. Sport and Exercise Psychology Review, 7, 23-27.

19 Bartholomew, K., Ntoumanis, N., Ryan, R.M., \& Thøgersen-Ntoumani, C. (2011). Psychological need thwarting in the sport context: Assessing the darker side of athletes experience. Journal of Sport and Exercise Psychology, 33, 75-102. 
1 Bartholomew, K., Ntoumanis, N., Cuevas-Campos, R., \& Lonsdale, C. (2014). Job pressure and

2 ill-health in physical education teachers: The mediating role of psychological need thwarting. Teaching and Teacher Education, 37, 101-107. doi: 10.1016/j.tate.2013.10.006

4 Blanchard, C. M., Amiot, C. E., Perreault, S., Vallerand, R. J., \& Provencher, P. (2009).

Cohesiveness, coach's interpersonal style and psychological needs: Their effects on selfdetermination and athletes' subjective well-being. Psychology of Sport \& Exercise, 10, 545551. doi: 10.1016/j.psychsport.2009.02.005

Block, J. (1995). A contrarian view of the five-factor approach to personality description. Psychological Bulletin, 117, 187-215. doi: 10.1037/0033-2909.117.2.187

Bosworth, K., Espelage, D. L., \& Simon, T. R. (1999). Factors associated with bullying behavior in middle school students. Journal of Early Adolescence, 19, 341-362. doi: $10.1177 / 0272431699019003003$

Brislin R. W. (1986). The wording and translation of research instruments. In W. J. Lonner and J. W. Berry (Eds). Field methods in educational research (pp. 137 - 164). Newbury Park, CA: Sage.

Cheon, S. H., \& Reeve, J. A. (2015). Classroom-based intervention to help teachers decrease students' amotivation. Contemporary Educational Psychology,40, 99-111. http://dx.doi.org/10.1016/j.cedpsych.2014.06.004

D’Arripe-Longueville, F., Fournier, J. F., \& Dubois, A. (1998). The perceived effectiveness of interactions between expert French judo coaches and elite female athletes. The Sport Psychologist, 12, 317-332.

Deci, E. L., \& Ryan, R. M. (1985). Intrinsic Motivation and Self-determination in Human Behavior. New York: Plenum Press. 
1 Deci, E. L., Koestner, R., \& Ryan, R. M. (1999). A meta-analytic review of experiments

2 examining the effects of extrinsic rewards on intrinsic motivation. Psychological Bulletin, $3 \quad 125,627-668$.

4 Deci, E. L., \& Ryan, R. M. (2000). The "what" and "why" of goal pursuits: Human needs and 5 the self-determination of behavior. Psychological Inquiry, 11, 227-268. doi:

7 Demaray, M. K., \& Malecki, C. K. (2002). Critical levels of perceived social support associated

$$
\text { 10.1207/S15327965PLI1104_01 }
$$
with student adjustment. School Psychology Quarterly, 17(3), 213-241. doi: 10.1521/scpq.17.3.213.20883

De Meyer, J., Tallir, I. B., Soenens, B., Vansteenkiste, M., Aelterman, N., Speleers, L., \& Haerens, L. (2014). Does observed controlling teaching behavior relate to students' motivation in physical education? Journal of Educational Psychology, 106(2), 541-554. doi: $10.1037 / \mathrm{a} 0034399$

Dodge, K. A. (1991). The structure and function on reactive and proactive aggression. In D.J. Pepler \& K. H. Rubin (Eds). The development and treatment of child aggression (pp. 201216). Hillsdale, NJ: Lawrence Erlbaum.

Espelage, D. L., Bosworth, K., \& Simon, T. R. (2000). Examining the social context of bullying behaviors in early adolescence. Journal of Counseling \& Development, 78, 78-85. doi: 10.1002/j.1556-6676.2000.tb01914.x

Flink, C., Boggiano, A. K., \& Barrett, M. (1990). Controlling teaching strategies: Undermining children's self-determination and performance. Journal of Personality and Social Psychology, 59, 916-924. doi: 10.1037//0022-3514.59.5.916 
1 Fraser, B. J. (1989). Twenty years of classroom climate work: Progress and prospect. Journal of

2 Curriculum Studies, 21, 307-327. doi: 10.1080/0022027890210402

3 Hagger, M. S. (2014). Avoiding the "déjà-variable" phenomenon: Social psychology needs more

4 guides to constructs. Frontiers in Psychology, 5, 52. doi: 10.3389/fpsyg.2014.00052

5 Hagger, M. S., \& Chatzisarantis, N. L. D. (2007). Advances in self-determination theory research

6 in sport and exercise. Psychology of Sport and Exercise, 8, 597-599. doi:

$7 \quad$ 10.1016/j.psychsport.2007.06.003

8 Hagger, M. S., Chatzisarantis, N. L. D., \& Harris, J. (2006). The process by which relative

9 autonomous motivation affects intentional behavior: Comparing effects across dieting and 10 exercise behaviors. Motivation and Emotion, 30, 306-320. doi: 10.1007/s11031-006-9046-5

11 Hagger, M. S., Chatzisarantis, N. L. D., Hein, V., Soós, I., Karsai, I., Lintunen, T., \& Leemans, S

12 (2009). Teacher, peer, and parent autonomy support in physical education and leisure-time

13 physical activity: A trans-contextual model of motivation in four nations. Psychology and

14 Health, 24, 689-711. doi: 10.1080/08870440801956192

15 Hawley, P. H., Little, T. D., \& Pasupathi, M. (2002). Winning friends and infuencing peers:

16 Strategies of peer infuence in late childhood. International Journal of Behavioral

17 Development, 26, 466-474. doi: 10.1080/01650250143000427

18 Heck, R. H., Thomas, S. L., \& Tabata, L. N. (2010). Multilevel and longitudinal modeling with

19 IMB SPSS. Routledge, Taylor \& Francis Group.

20 Henderlong, J., \& Lepper, M. R. (2002). The effects of praise on children's intrinsic motivation:

21 A review and synthesis. Psychological Bulletin, 128, 774-795. doi: 10.1037//0033-

$22 \quad 2909.128 .5 .774$ 
1 Hollembeak, J., \& Amorose, A. J. (2005). Perceived coaching behaviors and college athletes'

2 intrinsic motivation: A test of self-determination theory. Journal of Applied Sport

3 Psychology, 17, 20-36. doi: 10.1080/10413200590907540

4 Horn, T. S. (1985). Coaches' feedback and changes in children's perceptions of their physical 5 competence. Journal of Educational Psychology, 77, 174-186. doi: 10.1037//0022-

$6 \quad 0663.77 .2 .174$

7 Hu, L., \& Bentler, P. M. (1999). Cutoff criteria for fit indexes in covariance structure analysis:

8 Conventional criteria versus new alternatives. Structural Equation Modeling, 6, 1-55. doi:

$9 \quad 10.1080 / 10705519909540118$

10 Jansen, P. W., Verlinden, M., Berkel, A. D., Mieloo, C., van der Ende, J., Veenstra, R., Verhulst,

11 F. C., Jansen, W., \& Tiemeier, H. (2012). Prevalence of bullying and victimization among

12 children in early elementary school: Do family and school neighbourhood socioeconomic

13 status matter? BMC Public Health, 12, 494. doi:10.1186/1471-2458-12-494

14 Kohn, A. (1993). Punished by rewards: The trouble with gold stars, incentive plans, A's, praise,

15 and other bribes. New York: Houghton Mifflin.

16 Mageau, G. A., \& Vallerand, R. J. (2003). The coach-athlete relationship: A motivational model.

17 Journal of Sports Sciences, 21, 883-904. doi: 10.1080/0264041031000140374

18 Monks, C. P., \& Smith, P. K. (2006). Definitions of bullying: Age differences in understanding

19 of the term, and the role of experience. British Journal of Developmental Psychology, 24,

20 801-821. doi: $10.1348 / 026151005 X 82352$

21 Mulaik, S. A., \& Millsap, R. E. (2000). Doing the four-step right. Structural Equation Modeling,

22 7, 36-73. doi: 10.1207/S15328007SEM0701_02

23 Nansel, T. R., Craig, W., Overpeck, M. D., Saluja, G., \& Ruan, W. J. (2004). Cross-national 
consistency in the relationship between bullying behaviors and psychosocial adjustment. Archives of Pediatric and Adolescent Medicine, 158, 730-736. doi: 10.1001/archpedi.158.8.730

Niemiec, C. P., Ryan, R. M., \& Deci, E. L. (2009). The path taken: Consequences of attaining intrinsic and extrinsic aspirations in post-college life. Journal of Research in Personality, 43, 291-306. doi: 10.1016/j.jrp.2008.09.001

Ntoumanis, N., \& Standage, M. (2009). Motivation in physical education classes: A selfdetermination theory perspective. Journal of Research and Theory in Education, 7, 194-202. doi: $10.1177 / 1477878509104324$

Ormerod, M. B. (1975). Subject preference and choice in coeducational and single sex secondary schools. British Journal of Educational Psychology, 45, 257-267. doi: 10.1111/j.20448279.1975.tb02963.x

Pelletier, L. G., Fortier, M. S., Vallerand, R. J., \& Briere, N. M. (2001). Associations among perceived autonomy support, forms of self-regulation, and persistence: A prospective study. Motivation \& Emotion, 25, 279-306. doi: 10.1023/A:1014805132406

Pihu, M., Hein, V., Koka, A., \& Hagger, M. S. (2008). How students' perceptions of teachers' autonomy-supportive behaviours affect physical activity behaviour: an application of the trans-contextual model. European Journal of Sport Science, 4, 193-204. doi: $10.1080 / 17461390802067679$

Price, J. M., \& Dodge, K. A. (1989). Reactive and proactive aggression in childhood: Relations to peer status and social context dimensions. Journal of Abnormal Child Psychology, 17, 455-471. doi: 10.1007/BF00915038

Reeve J., \& Halusic, M. (2009) How K-12 teachers can put self-determination theory principles 
into practice. Theory and Research in Education, 7, 145-154. doi: $10.1177 / 1477878509104319$

Reeve J., \& Jang, H. S. (2006). What teachers say and do to support students' autonomy during a learning activity. Journal of Educational Psychology, 98, 209-218. doi: 10.1037/00220663.98.1.209

Reeve, J., \& Ching-Mei Tseng, C.-M. (2011). Cortisol reactivity to a teacher's motivating style: The biology of being controlled versus supporting autonomy. Motivation and Emotion, 35, 63-74. doi: 10.1007/s11031-011-9204-2

Rigdon, E. E. (1999). Using the Friedman method of ranks for model comparison in structural equation modelling. Structural Equation Modelling: A Multidisciplinary Journal, 3, 219_ 232. doi:10.1080/10705519909540131

Rigby, K. (2002). New perspectives on bullying. London \& Philadelphia: Jessica Kingsley.

Ryan, R. M., \& Deci, E. L. (2000). Intrinsic and extrinsic motivations: Classic definitions and new directions. Contemporary Educational Psychology. 25, 54-67. doi: 10.1006/ceps.1999.1020

Ryan, R. M., Deci, E. L., Grolnick, W. S., \& La Guardia, J. G. (2006). The significance of autonomy and autonomy support in psychological development and psychopathology. In D. Cicchetti \& D. J. Cohen (Eds.), Developmental psychopathology: Theory and method 2nd ed., (Vol. 1, pp. 795-849). New Jersey: John Wiley \& Sons, Inc.

Ryan, R. M., Patrick, H., Deci, E. L., \& Williams, G. C. (2008). Facilitating health behaviour change and its maintenance: Interventions based on self-determination theory. The European Health Psychologist, 10, 2-5.

Salmivalli, C., \& Peets, K. (2009). Bullies, victims, and bully-victim relationships. In K. Rubin, 
W. Bukowski, \& B. Laursen (Eds.), Handbook of peer interactions, relationships and groups (pp. 322-340). New York, NY: Guilford Press.

3 Scriven, M. (1988). The validity of student ratings. Instructional Evaluation, 9, 5-18.

4 Silk, J. S., Morris, A. S., Kanaya, T., \& Steinberg, L. (2003). Psychological control and autonomy granting: Opposite ends of a continuum or distinct constructs? Journal of Research on Adolescence, 13, 113-128. doi: 10.1111/1532-7795.1301004

Sheldon, K. M., Elliot, A. J., Kim, Y., \& Kasser, T. (2001). What's satisfying about satisfying events? Comparing ten candidate psychological needs. Journal of Personality and Social Psychology, 80, 325-339. doi: 10.1037//0022-3514.80.2.325

Skinner, E. A. (1996). A guide to constructs of control. Journal of Personality and Social Psychology, 71, 549 - 570. doi: 10.1037/0022-3514.71.3.549

Skinner, E. A., \& Wellborn, J. G. (1994). Coping during childhood and adolescence: A motivational perspective. In D. L. Featherman, R. M. Lerner, \& M. Perlmutter (Eds.), Lifespan development and behavior (Vol. 12, pp. 91-133). Hillsdale, NJ: Erlbaum.

Soenens, B., Sierens, E., Vansteenkiste, M., Dochy, F., \& Goosens, L. (2012). Psychologically controlling teaching: Examining outcomes, antecedents, and mediators. Journal of Educational Psychology, 104, 108-120. doi: 10.1037/a0025742

Stables, A., \& Wikeley, F. (1997). Changes in preference for and perceptions of relative importance of subjects during a period of educational reform. Educational Studies, 23, 393403. doi:10.1080/0305569970230305

Tessier, D., Sarrazin, P., \& Ntoumanis, N. (2008). The effects of an experimental programme to support students' autonomy on the overt behaviors of physical education teachers. European Journal of Psychology of Education, 23, 239-253. doi: 10.1007/BF03172998 
1 Taylor, I., Ntoumanis, N., \& Standage, M. (2008). A self-determination theory approach to 2 understanding antecedents of teachers' motivational strategies in physical education. Journal 3 of Sport and Exercise Psychology, 30, 75-94.

4 Vansteenkiste, M., \& Ryan, R. M. (2013). On psychological growth and vulnerability: Basic $5 \quad$ psychological need satisfaction and need frustration as a unifying principle. Journal of $6 \quad$ Psychotherapy Integration, 23(3), 263-280. doi: 10.1037/a0032359

7 Ziegler S., Rosenstein-Manner, M., \& Toronto Board of Education. (1991). Bullying at school: 8 Toronto in an international context. Toronto: Toronto Board of Education. 
${ }^{1}$ It is important to note that our conceptualization and definition of "controlling

3 behaviours" is confined to the definition from self-determination theory i.e. the interpersonal

4 style and actions of significant others (e.g., teachers) that reflect or communicate that the

5 behaviour and outcomes of individuals in a particular context (e.g., students) are determined by

6 others and external forces. It should be considered distinct from other conceptualizations of the

7 construct of control, which generally reflects beliefs about capacity to engage in actions and

8 agency (for a review see Skinner, 1996). From Skinner's perspective, our definition of

9 "controlling behaviours" is most closely aligned with constructs that reflect coercion. We have

10 taken care to ensure that we refer specifically to "controlling behaviours" rather than "control" in

11 order to avoid terminological confusion and "jingle" fallacies i.e. referring to different constructs

12 using the same term (Block, 1995; Hagger, 2014).

$13 \quad{ }^{2}$ Due to the hierarchical nature of the data (i.e., student data nested in classes and

14 schools), we explored the use of multilevel analysis to analyse the data. The data available,

15 however, only enabled us to analyse the two-level model (i.e., students at level 1 and schools at

16 level 2). To determine how much of the total variance in each study variable could be attributed

17 to between-school variability we conducted a series of separate null or no-predictor models.

18 These models are considered the first step in developing multilevel models according to the

19 recommendations of Heck, Thomas, and Tabata (2010). In each model, each study variable was

20 specified as the dependent variable and school as grouping variable. Results indicated that the

21 intercepts did not vary significantly across schools (Wald Zs $=.28-1.72 \mathrm{ps}>.05$ ) for all of the

22 study variables. The intraclass correlations (ICC) for most of the study variables suggested that

23 only between 0.5 and $5.4 \%$ of the total variability between schools could be attributed to 
1 between-school variability. The only exception was the model for the teacher's controlling

2 behaviour such as intimidation variable which suggested that $10.5 \%$ of the total variability was

3 attributable to between-school variability. On the other hand, results of the null models indicated

4 that significant proportions of the total variance could be explained from within student

5 variability for all study variables without exception (Wald Zs $=17.02-17.20$; ps <.001). Since

6 the results of null models indicated that the total variability in study variables attributable to

7 between-school variability was minimal for all but one of the factors, we deemed that conducting

8 a multilevel analysis would add a little advantage as the higher level grouping had an

9 unsubstantive effect in explaining variability in the study variables. Thus, an analysis conducted

10 at the individual level (i.e., student level) would be optimal. We also fit a multilevel SEM using

11 LISREL 8.8 that included both between group (i.e., school level) and within group (i.e., student

12 level) effects to our two-level dataset $\left(\chi^{2}(509)=1092,56\right.$, RMSEA $=.061, \mathrm{CI}_{90}$ for RMSEA

13 range $=.056-.066$ ). Results of the multilevel SEM indicated that school level effects were not

14 statistically significant, but student-level effects remained statistically significant with identical

15 pattern to the single level model depicted in Figure 1. Therefore the SEM with student-level

16 effects only seems to be the most appropriate. With regard to the teacher's controlling behaviour

17 such as intimidation, however, we caution the reader about the fact that in addition to the

18 significant variance explained between students, a substantial amount of variability was also

19 found between schools for this particular variable.

$20 \quad{ }^{3} \mathrm{We}$ also tested two alternative models and compared those against the hypothesized

21 model depicted in Figure 1. In both alternative models, the direct paths from all of the

22 dimensions of perceived teachers' controlling behaviour to perceived need thwarting were

23 specified. In the first alternative model, only direct paths from perceived need thwarting to anger 
1 and from anger to bullying were specified, whereas in the second alternative model only direct

2 paths from perceived need thwarting to bullying and from bullying to anger were specified.

3 Results of the both alternative models exhibited acceptable fit to the data $\left[\chi^{2}(239)=705.12\right.$, CFI

$4=.96, \mathrm{NFI}=.95, \mathrm{NNFI}=.96, \mathrm{RMSEA}=.057, \mathrm{CI}_{90}$ for RMSEA range $=.052-.062$ and $\chi^{2}(239)$

$5=745.93, \mathrm{CFI}=.96, \mathrm{NFI}=.94, \mathrm{NNFI}=.96, \mathrm{RMSEA}=.060, \mathrm{CI} \mathrm{I}_{90}$ for $\mathrm{RMSEA}$ range $=.055-.064$

6 for the first and second alternative model, respectively]. The model AIC was 828.33, 827.12, and

7867.93 for the hypothesized model, first alternative model, and second alternative model,

8 respectively. According to the Rigdon (1999), lower model AIC values indicate a better fit.

9 Although the model AIC values for hypothesized model and first alternative model were almost

10 identical, the hypothesized model was deemed to be the best fitted model as it included also a

11 direct path from perceived need thwarting to bullying representing thus better the real life

12 situation. 